\title{
The link between allergic rhinitis and asthma: A role for antileukotrienes?
}

\author{
H Kim $M D^{1,2}$, J Bouchard $M D^{3}$, PM Renzi MD ${ }^{4}$
}

\begin{abstract}
H Kim, J Bouchard, PM Renzi. The link between allergic rhinitis and asthma: A role for antileukotrienes? Can Respir J 2008; 15(2):91-98.

Allergic rhinitis and asthma are both chronic heterogeneous disorders, with an overlapping epidemiology of prevalence, health care costs and social costs in quality of life. Both are inflammatory disorders with a similar pathophysiology, and both share some treatment approaches. However, each disorder has an array of treatments used separately in controlling these atopic disorders, from inhaled corticosteroids, beta ${ }_{2}$-agonists and antihistamines to newer monoclonal antibody-based treatments. The present article reviews the shared components of allergic rhinitis and asthma, and examines recent evidence supporting antileukotrienes as effective agents in reducing the symptoms of both diseases.
\end{abstract}

\section{Le lien entre la rhinite allergique et l'asthme : Un rôle pour les antileukotriènes?}

La rhinite allergique et l'asthme sont deux troubles hétérogènes chroniques dont l'épidémiologie de la prévalence, les coûts de santé et les coûts sociaux en matière de qualité de vie se chevauchent. Ce sont deux troubles inflammatoires à la physiopathologie similaire, et tous deux partagent certaines approches thérapeutiques. Cependant, chacun de ces troubles atopiques comporte toute une série de traitements de contrôle utilisés séparément, qu'il s'agisse des corticoïdes en aérosol, des bêta 2 agonistes et des antihistaminiques ou des traitements plus récents à base d'anticorps monoclonaux. Le présent article passe en revue les éléments que partagent la rhinite allergique et l'asthme ainsi que les donnée probantes récentes qui appuient le rôle des antileukotriènes comme agents efficaces en vue de réduire les symptômes de ces deux maladies.

Key Words: Antileukotrienes; Asthma; Epidemiology; Pathophysiology; Rhinitis

\begin{abstract}
A llergic rhinitis $(A R)$ is one of the most common chronic disorders, with reported prevalences ranging from $3 \%$ to $19 \%$ in various countries (1). AR is a heterogeneous disorder that includes seasonal AR (SAR) symptoms ('hay fever') and the more difficult diagnostic category, perennial AR (PAR). One study (1) suggested that SAR is found in approximately $10 \%$ of the general population and PAR in $10 \%$ to $20 \%$. Other studies estimate even higher figures; for example, Meltzer (2) suggested that AR affects $25 \%$ of the general population and $40 \%$ of children.

Asthma is also a heterogeneous disorder, and as Wenzel (3) suggested, definitions of asthma are problematic because of its complexity, possibly reflecting a collection of different phenotypes. Most clinical definitions elaborate on the symptoms (eg, wheezing and difficulty breathing) of lung functions, of exacerbations and, often, of the response to medication (eg, high-dose corticosteroids) (3). It is estimated that asthma affects $4 \%$ to $11 \%$ of the general population (4). Evidence in Canada also suggests that the symptoms of patients with asthma continue to be inadequately controlled according to guidelines $(5,6)$.

In the literature, there is increasing recognition of a link between asthma and AR. It should be noted, however, that there are other patients: those with nonatopic asthma and those with non-AR. Although these disorders are beyond the scope of the present review, it is recognized that many patients

with nonallergic asthma have non-AR and/or sinusitis. The link between these problems may not be as close as the link between allergic asthma and AR; nevertheless, it has been supported by some studies.

Simons (7) reviewed some of the early concepts linking AR and asthma, and suggested that the connection between the two had actually been known for centuries, but that specialization in medicine, as well as in medications, led to the perspective of separate disease entities. To reconnect asthma and AR, Simons proposed using the term 'allergic rhinobronchitis'. Another current concept is 'one airway, one disease', which was originally suggested by Grossman in 1997 (8). It seems logical that an uninterrupted air passage from the nose to the alveolar ducts of the lungs would have many similarities. The following discussion elaborates on the connections between $\mathrm{AR}$ and asthma in terms of their epidemiology, pathophysiology and similar responses to treatment. Each of these disorders has a variety of effective treatment modalities; asthma responds well to inhaled corticosteroids and beta ${ }_{2}$-agonists, as well as to a new adjunctive therapy approved in Canada, the antiimmunoglobulin E (anti-IgE) agent omalizumab (9). Treatment for AR usually involves various forms of antihistamines and decongestants, as well as glucocorticosteroids (10). The focus of the present review is on a treatment that is effective for both disorders, in particular, the leukotriene receptor antagonists (LTRAs).
\end{abstract}

${ }^{1}$ McMaster University, Hamilton; ${ }^{2}$ University of Western Ontario, London, Ontario; ${ }^{3}$ St Joseph's Hospital, La Malbaie; ${ }^{4}$ University of Montreal, Montreal, Quebec

Correspondence: Dr PM Renzi, 2065 Alexandre de Sève Z8905, Montreal, Quebec H2L 2W5. Telephone 514-890-8000 ext 28031,

fax 514-412-7579, e-mail renzip@earthlink.net 


\section{EPIDEMIOLOGY}

The connection between AR and asthma has been the subject of many epidemiological investigations that have shown an important overlap between both diseases. In the early studies, $40 \%$ of AR patients had asthma, and $30 \%$ to $80 \%$ of asthmatic patients reported AR. Simons (7) suggested that these were probably underestimates of the relationship, because more recent, sensitive interview protocols found rhinitis in $98.9 \%$ of allergic subjects with asthma and in $78.4 \%$ of nonallergic subjects with asthma. Leynaert et al (8) reviewed several studies demonstrating the strong association between rhinitis per se and asthma, both in allergic and nonallergic subjects.

\section{ASSOCIATED COSTS}

In addition to the epidemiological relationship, some studies have investigated the costs of these disorders, as well as the effects of concomitant AR and asthma on health care and society. Separately, most estimates of the annual cost of AR range between US $\$ 2$ and US $\$ 5$ billion, depending on the aspects included (11). In 1990, the cost of illness related to asthma was estimated to be US $\$ 6.2$ billion, with inpatient hospital services accounting for US $\$ 1.6$ billion of the total (12). By 1998, however, the estimated cost of asthma in the United States (US) had risen to US $\$ 12.7$ billion (13). Malone et al (14) also examined the direct and indirect costs of AR based on the National Medical Expenditure Survey (NMES). In 1987, out of the estimated 39 million people in the US with AR, only 4.8 million $(12.3 \%)$ had sought medical treatment. The total estimated cost of the condition, in 1994 dollars, was US $\$ 1.23$ billion (95\% CI US $\$ 846$ million to US\$1.62 billion), and direct medical expenses accounted for $94 \%$ of the total costs. In addition, AR provoked approximately 811,000 missed workdays, 824,000 missed school days and 4,230,000 reduced activity days (14). Price et al (15) further reviewed the available data on the direct costs of AR in the US, and found that the totals were between US $\$ 1.2$ and US $\$ 3.4$ billion, compared with US $\$ 6.1$ billion for asthma. In an examination of children with both asthma and AR, Thomas et al (16) found that those with this comorbidity incurred more prescription drug costs, physician visits and hospital costs than children with asthma alone.

\section{QUALITY OF LIFE}

Quality of life $(\mathrm{QoL})$ is a measure used in many investigations. In general, QoL issues for adult rhinitis patients include fatigue, as well as decreases in energy, general health perception and social functioning. In children, problems may include learning impairments, an inability to integrate with peers, anxiety and family dysfunction. Generally, impairment increases with the number of symptoms and disease severity. Comorbid disorders are often associated with rhinitis, including sinusitis, otitis media and frequent respiratory infections, which can further compromise an individual's QoL. Asthma, as well, has similar effects on the QoL, but in addition to being a chronic disorder, asthma also carries a risk of fatality. A chronic or seasonal difficulty in breathing, whether caused by nasal or bronchial inflammation, is a critical burden. The restrictions on breathing can cause psychological problems because of anxiety and increased health care concerns, especially the desire to feel in control when dealing with one's health.

The symptoms provoked by both AR and asthma seriously affect an individual's ability to perform his or her normal daily life. In fact, Leynaert et al (17) reported that patients with both AR and asthma had experienced more physical limitations. Measures of QoL are usually based on questionnaires (eg, Rhinoconjunctivitis Quality of Life Questionnaire, Short Form 36) or visual analogue scales (eg, level of well-being, ranging from poor to excellent). The questionnaires comprise scores in a number of domains: nasal symptoms, eye symptoms, other symptoms, activity, sleep, emotions and practical problems. Given the prevalence of AR and asthma, it is clear that both the direct and indirect costs to the individual and the society are significant.

\section{PATHOPHYSIOLOGY}

The clearest connection between AR and asthma is based on a shared physiological response; both are part of the body's immune response to an identified foreign substance. The term often used for the response is 'allergy', and the foreign substance is an allergen. Kay (18) notes that when Clemens von Pirquet originally introduced the term allergy in 1906, he had applied it to the reactivity found in both protective immunity and hypersensitivity. However, allergy is now identified with the type 1 hypersensitivity disorder of the immune system associated with $\operatorname{IgE}$.

The normal response to an aeroallergen is the production of immunoglobulins or antibodies to the allergens. Some individuals appear to be genetically predisposed to produce more IgE, in particular, in response to an allergen. The individual is then sensitized to this allergen, and many allergen-specific $\operatorname{IgE}$ molecules attach themselves to mast cells in the protective tissues, particularly in the mucous membranes (2).

In addition to mast cells, numerous other inflammatory cells exist in the mucous membranes. Laitinen et al (19) have documented the airway inflammatory process involving several cell types in patients with an early diagnosis of asthma; these cells, (CD4+ T cells, macrophages, B cells, basophils and neutrophils) are essential in the immune reaction. When an allergen is presented, inflammatory cells and their progenitors immediately begin to proliferate in the bone marrow and move into the circulation (20). IgE molecules on the mast cells rapidly bind to the allergen, and after several $\mathrm{IgE}$ molecules are bound, the cross-linkages between them cause the mast cell to degranulate, releasing preformed mediators from the cell and initiating the production of other mediators (eg, chemokines and chemotactic factors) in the inflammatory cascade. The mast cell releases the most well-known preformed mediator, histamine, and others, including leukotrienes, tryptase, prostaglandins and platelet-activating factor $(18,21)$. Histamine and the other mediators produce the characteristic acute allergic rhinoconjunctivitis symptoms (eg, sneezing, rhinorrhea, conjunctivitis).

Some of the symptoms of this acute response may resolve, but the inflammatory cascade continues to involve other cells of the mucosa, and a continued response is provoked by further activation of mast cells, dendritic cells and T cells. T cells are the immune regulatory cells that can differentiate into $\mathrm{T}$ helper (Th) cells Th1 and Th2. The critical Th2 allergic response is the release of cytokines (eg, interleukin [IL]-3, IL-4, IL-5 and IL-13) that continue the inflammatory reactions and promote further production of $\operatorname{IgE}$ by plasma cells (10). IL-5 is responsible, in association with the CC chemokine eotaxin, for mobilizing the bone marrow to produce and release eosinophils into the 
blood stream. They are then locally recruited through chemoattraction (eotaxin mediation) to the tissue sites of allergic inflammation (22). Thus, cytokines influence a wide range of events associated with chronic inflammation, including eosinophil recruitment and the consequent release of cysteinyl leukotrienes (CysLTs) and other inflammatory mediators. The effect of the CysLTs, products of an arachidonic acid pathway, is of particular importance in linking the inflammation of AR and asthma, as will be discussed in the section on treatment response.

The inflammatory response is similar for both $A R$ and asthma; they share a similar respiratory epithelial structure of ciliated pseudostratified columnar epithelium with goblet cells (7). The pathophysiologies of local mediator release, systemic immune response and eosinophil recruitment are alike. During the early-phase response, symptoms in patients with AR typically consist of sneezing, rhinorrhea and conjunctivitis; patients with asthma experience wheezing, coughing and shortness of breath, in addition to objectively demonstrable changes in lung function. There is a similar pattern and time course of early- and late-phase responses in AR and asthma. Approximately $1 \mathrm{~h}$ after allergen provocation, patients with AR experience a peak in symptoms, while patients with asthma experience a steep decline in lung function, measured by forced expiratory volume in $1 \mathrm{~s}\left(\mathrm{FEV}_{1}\right)$. During the late-phase response, nasal congestion is sustained in patients with $A R$, while a prolonged fall in lung function is again observed in patients with asthma. Within $12 \mathrm{~h}$ to $24 \mathrm{~h}$, both types of reactions typically resolve.

\section{ATOPY - A CONNECTION}

The link between the epidemiology and pathophysiology of $\mathrm{AR}$ and asthma can be seen in the worldwide increase in atopic disorders. AR and asthma have markedly increased in western Europe, North America and Australasia in recent years (18). For example, according to Canadian statistics, the percentage of the population in Canada with asthma has been steadily rising, from $6.4 \%$ in 1995 to 1996 , to $8.4 \%$ in 2000 to 2001. The percentage of women with asthma particularly increased: $6.7 \%$ of women had asthma in 1995 to 1996 and $9.9 \%$ in 2000 to 2001 (23). Several studies have indicated that the prevalence of AR is increasing, and data similar to asthma have been found (24). For example, Skoner (1) noted that in Swedish army studies, hay fever prevalence increased from $4 \%$ to $8 \%$ between 1971 and 1981, and over an eight-year period in Arizona, skin test reactivity rose from 35\% to 50\%. Recent reviews, however, have revealed conflicting temporal trends since 1990 in the prevalence of both asthma and atopy in various parts of the world (25). Nevertheless, some studies suggest that increases in these disorders appear to be related to the changing environment of the Western lifestyle. In fact, this has been termed the 'hygiene hypothesis', because since World War II, there has been a massive increase in the use of soaps and antibacterials of all types. As a result, the populations in these countries have been less exposed to early immunizing pathogens and have fewer early childhood infections. Kay (18) reviewed a few population studies; for example, since German reunification, there have been increased prevalences of atopy and hay fever in East German children (18). Epidemiological studies also support this idea; particular colonizing bacteria (eg, Lactobacillus species and eubacteria) in the intestinal tract can prevent atopic sensitization and are found in children from areas with a low prevalence of atopy (18). Von Ehrenstein et al (26) found that living on farms with a high degree of exposure to livestock-associated bacteria was protective against allergic disorders in children. The mechanism suggested for this effect involved the balance of $\mathrm{T}$ cells.

Healthy individuals have a balance of Th1 and Th2 cells. In utero, the fetus is Th2 cell-dominant in accordance with the placental milieu, for reasons related to fetal rejection. After birth, exposure to environmental microbes stimulates the development of Th1 responses and produces the necessary balance between the two immune responses. In Western cultures, more often, the developing immune system may be deprived of microbial antigens that stimulate Th1 cells, leading to a phenotype that expresses more Th2 cells essential in the allergic response. In fact, Stern et al (27) provided evidence of specific allergen-dependent switching patterns in Th2-dependent immunoglobulins in people with farm exposure. The relationships among asthma, AR and atopy, however, are still subjects of research and debate $(25,28)$. In particular, interest has focused on other environmental factors; for example, Kohlhammer et al (29) examined the relationship between physical inactivity and hay fever in children. Although the physiological mechanisms could not be clarified because no increased allergic sensitization could be found, nevertheless, physical activity appeared protective, because higher rates of hay fever were seen in inactive children. Kohlhammer et al (30) also examined the exposure to chlorination by-products (ie, swimming pool use) and hay fever; the results suggested an association. Finally, Radon and Schulze (31) investigated two elements of the Western lifestyle and their effects on allergic sensitization. Obesity and microbial exposure were selected as markers; the results revealed that nonobese, farm-exposed subjects had reduced sensitization compared with those with no farm exposure, but this decrease in sensitization was not found in obese subjects both with and without farm exposure. Therefore, the protective effects of increased microbial exposure were eliminated by obesity (31). This is one among many other factors that remain to be elucidated in understanding the genetic and environmental triggers of atopic disorders.

\section{CLINICAL EVIDENCE}

The support for the connection between AR and asthma has been given impetus with a series of elegant studies by Braunstahl et al $(32,33)$ on tissue response to allergen provocation. These studies were designed to elucidate the pathophysiological connections between the nose and the lungs. The first study compared allergic inflammation and clinical findings from the upper and lower airways after segmental bronchial provocation (SBP) with an allergen. Baseline nasal and bronchial specimens were collected from patients and controls before and after SBP. The allergic inflammatory response was determined by comparing the specimens at baseline, and $1 \mathrm{~h}$ and $24 \mathrm{~h}$ after SBP (bronchial biopsy only after $24 \mathrm{~h}$ ). Signs and symptoms were recorded for each time point. The specimens were examined for mucosal allergic inflammation, and evaluated for the presence of eosinophils, IL-5+ cells and eotaxin+ cells (necessary for eosinophil survival and chemotaxis). The study selected eight AR patients (with symptoms and skin-prick test confirmation) and eight nonallergic, healthy controls (32).

The second study had a similar provocation except that this time, instead of the bronchi, the nasal passages were stimulated 


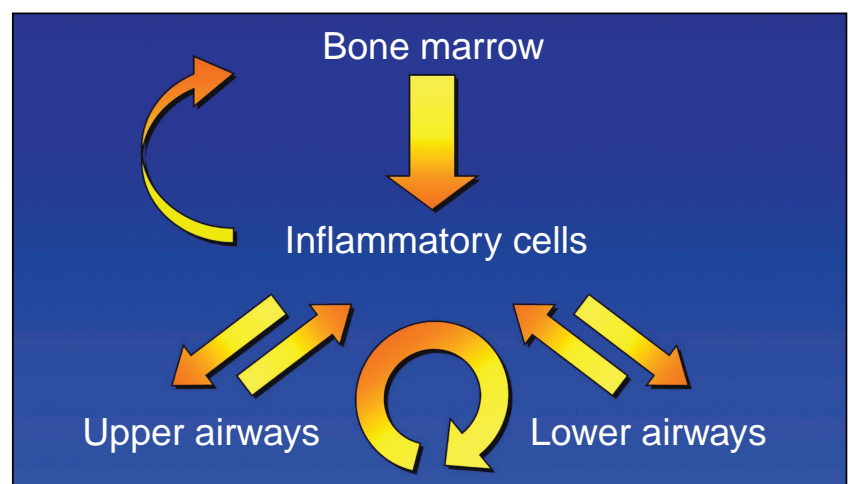

Figure 1) The inflammatory process involves crosstalk among the bone marrow, the inflammatory cells, and the upper and lower airways. Adapted from references 25 and 26

(33). Two groups of patients, nine with AR and nine nonallergic, healthy controls, were selected for the study. Blood samples, as well as bronchial and nasal biopsy specimens, were collected from the participants before nasal provocation and $24 \mathrm{~h}$ after provocation. Other measures included nasal and bronchial symptom scores (visual analogue scale), peak nasal inspiratory flow (PNIF) and peak expiratory flow (PEF; lung function measures). These measures were examined at baseline, after $0.5 \mathrm{~h}$ and every $2 \mathrm{~h}$ for $12 \mathrm{~h}$, and at day 2 .

In the first study with bronchial provocation, baseline tissue staining revealed greater numbers of eosinophils (tissue indicators for an allergic response) in allergic patients (32). Although the allergen was specifically directed to the lungs, both nasal and bronchial tissue exhibited significant increases in cells of the inflammatory cascade. These results suggested a general systemic activation of eosinophils and migration to the mucosa of both the upper and lower airways, ie, a shared inflammatory response even with exposure only in bronchial tissue.

The second study was also designed to examine the pathophysiological interactions between the upper and lower airways, but in this case, using nasal allergen provocation (33). At baseline, the subjects in the study were comparable, but after nasal provocation, the AR patients had lower values of PEF, and the PNIF revealed a bimodal curve of reduced air flow. Minimal changes were seen in the control subjects. In AR subjects, symptoms and the PNIF returned to baseline after $24 \mathrm{~h}$, but the PEF continued to show a reduced air flow. These results suggest that allergen nasal activation affects the entire epithelium of the airways, and stimulates crosstalk between the nasal and bronchial mucosa.

Taken together, results suggest that allergen challenge in any part of the airways leads to differentiation and migration of progenitors from the bone marrow, and directly or indirectly affects both upper and lower airway function (Figure 1).

\section{TREATMENT APPROACHES}

The Canadian Rhinitis Working Group (10) and the Allergic Rhinitis and its Impact on Asthma (ARIA) initiative workshop are two groups that have elaborated guidelines for the treatment of AR and asthma $(10,34)$. The consensus statement by van Cauwenberge et al (24), for example, reiterated the need for a careful diagnosis to differentiate AR from other comorbid conditions. If confirmed, the avoidance of allergens is a first step in reducing the allergic response; however, as
Platts-Mills (35) had pointed out, even this step is not that clear cut. In addition, the recognition of the connection between AR and asthma, both temporally and symptomatically, supports investigations into treatment of both disorders. The recognition that a similar mechanism of disease generation underlies AR and asthma offers the opportunity for rational treatment.

Treatment has primarily focused on the interruption of the inflammatory cascade by blocking the actions of chemicals released by the allergic response in the epithelium. The most well-known mediator for the development of AR symptoms is histamine; antihistamines have proven very effective in reducing nasal symptoms, but are not as effective in reducing the nasal blockage of inflammation (24). As a result, antihistamines are often combined with oral decongestants (eg, pseudoephedrine) to reduce nasal symptoms.

Topical corticosteroids are another possible treatment choice in AR to reduce nasal blockage. These substances are used as a wet or dry powder nasal spray and have a strong antiinflammatory capacity. Corticosteroids reduce cytokine and chemokine release, and reduce inflammatory cell infiltration of the mucosa (24). Minshall et al (36) investigated the action of mometasone furoate nasal spray on nasal tissues. The nasal biopsies demonstrated an attenuation of the inflammatory process and no adverse tissue changes in the mucosa, even after long-term use. Similarly, inhaled corticosteroids are an effective treatment for bronchoconstriction in asthma.

\section{CysLTs}

A more recent development in the interruption of the inflammatory cascade is the focus on CysLTs. Leukotrienes are one of the primary inflammatory mediators produced from arachidonic acid, and are released by mast cells, basophils, neutrophils and esosinophils in the reaction to an allergen (37). Leukotrienes are instrumental in causing the symptoms of SAR; they appear to play a critical role in nasal congestion by increasing vascular permeability and the pooling of blood in the venous sinuses. High levels of CysLTs have been found in the nasal secretions of patients with SAR. Recent research has examined polymorphisms in the leukotriene pathway that offer genetic underpinnings for the variable responses to treatment with agents that block the CysLTs (38). These antileukotrienes have improved the symptoms of asthma and AR, as discussed below.

\section{AR TREATMENT}

Chervinsky et al (39) examined the therapeutic effects of montelukast, an agent that interferes with the CysLT inflammatory process by specifically blocking the CysLT1 receptor, ie, an LTRA or antileukotriene. Montelukast was evaluated in patients with AR based on the relationship to levels of pollen exposure during three consecutive fall allergy seasons. During the seasons of 1999, 2000 and 2001, multicentre, randomized, double-blind, placebo-controlled and parallel-group trials were conducted. Following a three- to five-day placebo run-in period, the active treatment phase was two weeks in the first two seasons and four weeks in the third season, with the first two weeks used in the analysis for comparing primary efficacy. Patients were randomly assigned to $10 \mathrm{mg}$ of montelukast $(n=929)$ and placebo $(n=933)$ to be taken in the morning (study 3) or in the evening (studies 1 and 2). Another group was assigned loratadine $(20 \mathrm{mg})$ as a positive control, but these results were discussed in another analysis. 
The primary end point was the combined daytime nasal symptoms score based on patient diaries of nasal congestion, rhinorrhea, nasal itching and sneezing. Secondary end points included the individual component symptoms, nighttime symptoms, eye symptoms, rhinoconjunctivitis, QoL scores and peripheral blood eosinophils. In the combined analysis, montelukast significantly reduced the daytime nasal symptoms score. When the patient population was divided into subgroups, defined by tertiles of average pollen exposure distribution, the results of montelukast treatment differed relative to the level of pollen exposure. In the lower one-third, the treatment effect was not significant compared with placebo, but treatment was significantly effective with greater pollen exposure (upper two tertiles). A study by Mucha et al (37) compared the effects of montelukast $(10 \mathrm{mg})$ with a decongestant, pseudoephedrine $(240 \mathrm{mg}$ ), over a two-week treatment period, during allergy season. Both treatments had decreased the symptoms experienced by patients with SAR, improved the QoL and increased nasal air flow. Thus, montelukast is as effective as a decongestant on inflammation, and the effectiveness increases with higher allergen levels.

Philip et al (40) investigated the effectiveness and tolerability of an LTRA in the first large clinical trial to demonstrate the benefits of montelukast monotherapy in SAR. The randomized, double-blind, placebo-controlled, parallel-group trial was carried out in the spring of 2000 at 50 study centres in North America (43 in the US and seven in Canada). Montelukast (10 mg) was given once daily for two weeks to patients $(n=348)$ with AR; another group $(n=602)$ received loratadine (second-generation, nonsedating antihistamine as a positive control) and the third group $(\mathrm{n}=352)$ received a placebo. The trial had two periods: a three- to five-day run-in (a single-blind placebo) followed by the two-week treatment period. One thousand three hundred and two patients who met the inclusion criteria were randomly assigned and seen for five visits. A symptom diary card was completed daily by each patient during both periods; each night the daily symptoms evaluation was recorded, and the nighttime symptoms were recorded each morning. Other measures were the Rhinoconjunctivitis Quality of Life Questionnaire completed at the end of each of the two periods, a patient global evaluation of change in their AR, a global assessment by their physician, peripheral blood eosinophil counts before and after the double-blind treatment period, airborne pollen counts (grains $/ \mathrm{m}^{3}$ of air) measured daily for each geographical area, and finally, any reported adverse events or changes in physical examination. Both treatments demonstrated significant improvements from baseline in the daytime nasal symptoms score compared with placebo, as well as in the four individual symptoms comprising the score (ie, congestion, rhinorrhea, pruritus and sneezing). However, loratadine tended to be better than montelukast in improving daytime rhinorrhea, itching and sneezing. In addition, although both treatments significantly improved nighttime symptoms compared with placebo, numerically, the mean change from baseline symptom evaluations favoured montelukast over loratadine. In contrast to the results obtained with daytime symptoms compared with loratadine, montelukast improved nighttime symptoms overall and for each of the composite symptoms (difficulty going to sleep, nighttime awakenings and congestion on awakening).

The effectiveness of montelukast in improving the composite of daytime and nighttime symptoms, as well as daytime eye symptoms, in addition to the relatively greater improvement in nighttime symptoms, made the results nearly equivalent to loratadine, a known effective agent for AR. In fact, compared with placebo, montelukast was significantly more effective in improving all QoL parameters, as well as patient and physician global evaluations.

Another study by Patel et al (41) extended the treatment effectiveness of LTRAs to patients with PAR. In these patients, montelukast provided statistically significant improvements in symptoms over a six-week treatment period. Chen et al (42) approached the issue of PAR in children. This study compared the clinical efficacies of montelukast, cetirizine and placebo in the treatment of PAR in the first trial involving two- to six-year-old children. The results revealed that montelukast was as efficacious as cetirizine in improving all symptoms compared with placebo, except for nasal itching, for which cetirizine was more effective. However, montelukast was superior to cetirizine in improving night sleep quality.

In a recent systematic review and meta-analysis, Grainger and Drake-Lee (43) examined the evidence for montelukast efficacy in AR. They found that montelukast reduces nasal symptoms by $3.4 \%$ compared with placebo, but is not as effective as topical nasal steroids or antihistamines. As a result, they recommended montelukast as second-line therapy to be used in combination with an antihistamine.

\section{LTRAs IN CONCOMITANT AR AND ASTHMA}

LTRAs have been shown to be effective treatments in asthma. Barnes et al (44) analyzed the use of montelukast in patients with mild, persistent asthma and found that it improved control of asthma parameters (eg, $\mathrm{FEV}_{1}$ improved $7 \%$ to $8 \%$ over baseline). In some patients with stable asthma treated with inhaled corticosteroids, montelukast provides additional control of inflammation and improves QoL scores (45). In a national survey of montelukast treatment in routine practice by Barnes et al (46), the largest response was in patients with mild to moderate asthma. Overall, this LTRA was demonstrated to be an effective and well-tolerated treatment.

With the effectiveness of LTRAs in treating asthma, Meltzer (2) reviewed the studies on the efficacy of zafirlukast and montelukast in asthma, and explored the use of LTRAs in AR. This study found that the LTRA montelukast was an effective treatment for AR.

Recently, studies have been developed to examine the effectiveness of LTRA treatment in patients with both AR and asthma. Piatti et al (47) carried out an observational study of patients with $A R$ and bronchial asthma during allergy season and found that zafirlukast significantly reduced asthma and AR symptoms $(\mathrm{P} \leq 0.05)$, supporting the use of LTRA treatment for both disorders.

In an earlier study by Philip et al (40), one of the more interesting and provocative observations was a difference in peripheral blood eosinophil counts. Montelukast significantly decreased these counts compared with placebo, and this result was in contrast to loratadine, with which there were no eosinophil effects. The $17 \%$ median decrease in eosinophils from baseline after two weeks of treatment was similar to results found in studies of montelukast therapy for asthma. Given that the pathophysiology of AR and asthma involve the inflammatory cascade and the eosinophil influx into nasal and bronchial mucosa, this systemic effect reflects the ability of 
montelukast to reduce the influx or activation of inflammatory cells (eg, eosinophils) and the secretion of CysLTs in the epithelium. This study provided important support for the use of montelukast in patients with both AR and asthma.

Philip et al (4) followed up the previous study with an evaluation of montelukast treatment for patients with symptomatic $\mathrm{AR}$ and active asthma during allergy season. In the spring and fall of 2003, a randomized, parallel-group, double-blind, doubledummy study was carried out at 52 centres in the US and Europe. The two groups were given montelulast $(n=415)$ and placebo $(n=416)$ in a single-blind run-in placebo period of three to five days and then two weeks of active treatment with daily dosing at bedtime. Patients kept daily symptom diaries; the primary end point was the daily rhinitis symptoms score, comprising the average of specific nasal symptoms during both day and night. Montelukast demonstrated significant efficacy in improving symptoms of SAR in patients with comorbid active asthma; the daily symptom score (primary end point) was reduced compared with placebo $(\mathrm{P} \leq 0.001)$, and despite a large placebo effect, both the nasal and the nighttime symptoms were significantly improved. As well, in a subgroup analysis based on asthma status at the start of the study, there was greater improvement in rhinitis symptoms in patients who had taken inhaled corticosteroids, had asthma symptoms two or more times per week, had an $\mathrm{FEV}_{1}$ less than $80 \%$ of predicted and had a $12 \%$ or greater reversal of airway obstruction with beta $_{2}$-agonist use at the start of the study (4). These results suggested that montelukast may be more effective in patients with more severe or symptomatic asthma. Studies of patients with both AR and asthma have indicated that comorbidity increases asthma symptoms and the need for beta-agonist rescue medication; it also causes a twofold increase in asthma attacks and an increased risk of hospitalization (48). Therefore, the treatment of both disorders is critical.

An early study of asthma, the Clinical Outcomes with Montelukast as a Partner Agent to Corticosteroid Therapy (COMPACT) study, randomly assigned 889 adults with asthma whose symptoms persisted despite the use of inhaled corticosteroids. In the original double-blind study, after a run-in period, patients received either $10 \mathrm{mg}$ of montelukast once daily plus $800 \mu \mathrm{g} /$ day of inhaled budesonide or $800 \mu \mathrm{g}$ of budesonide twice daily for 12 weeks.

The post hoc analysis of this study by Price et al (48) examined those patients with uncontrolled asthma who also had a positive history of AR, either SAR or PAR. The primary efficacy end point investigated was morning PEF (measured morning and evening before taking medication). Other end points included beta-agonist use, asthma-free days and nocturnal awakenings. The results of this study indicated that for the total group of asthmatic patients, montelukast was as effective as doubling the inhaled corticosteroids for improving morning PEF. In addition, montelukast was significantly better than doubling inhaled corticosteroids in those patients who had concomitant asthma and AR. There was a $9.2 \%$ increase in morning PEF from baseline in the montelukast plus budesonide group, compared with a $6 \%$ increase in the double budesonide group. In asthmatic patients with AR, beta-agonist use fell by $27.8 \%$ in the combined medication group, compared with a $21 \%$ decrease in the double budesonide group. One suggestion for the positive results in patients with concomitant rhinitis is that montelukast is more effective in improving the inflammation associated with nasal symptoms and asthma.
Certainly, over the 12 weeks of treatment, montelukast significantly improved lung function in these patients.

A further study by Busse et al (49) evaluated the efficacy of montelukast in a subpopulation of asthmatic patients with seasonal asthma symptoms. Again, based on the pathophysiology of the role CysLTs play in the process of increased airway responsiveness to allergen exposure, as well as in the activation and migration of eosinophils and dendritic cells to the bronchial mucosa, the study was designed to evaluate the effectiveness of blocking CysLTs. Montelukast was given to patients who had both asthma and seasonal aeroallergen sensitivity; after treatment for three weeks during the allergy season, the effects on symptom relief was compared with placebo. The results demonstrated that montelukast provided significant improvements in daytime asthma symptom scores from baseline. Secondarily, the montelukast group used less beta-agonists, had fewer nighttime symptoms and had improved PEF rates. In addition, for patients who had symptoms of AR, the global improvement in those symptoms at the end of treatment for the montelukast group was greater than with placebo. Further analysis indicated that for the montelukast group, those patients reporting improved daytime asthma symptoms also reported improved AR symptoms.

A recent study reflected the now accepted perspective of a unified allergic airway and investigated the best treatment. Barnes et al (50) examined 17 patients who completed the randomized, double-blind, crossover study, and found that both topical steroids and combined mediator antagonists (montelukast and cetirizine) reduced systemic inflammation, but only the corticosteroids reduced bronchial and nasal inflammatory markers (ie, the provocative concentration of methacholine causing a 20\% decrease in $\mathrm{FEV}_{1}$ and exhaled nitric oxide).

Finally, a study by Virchow and Bachert (51) was designed to use a real-life setting for testing the efficacy and safety of montelukast in adult patients with both asthma and AR. The multicentre phase IV study involved 5786 patients (2487 male patients, 3299 female patients) who were identified by the 3018 physicians participating in the study. All patients were required to have both disorders, as diagnosed by their physician. Baseline measures were recorded for symptoms, and the severity of both disorders was categorized, ie, intermittent, mild or moderate asthma, and intermittent or persistent AR. In addition, QoL was assessed in the four domains of sleep, work, everyday life and activity limitations. Each patient received $10 \mathrm{mg}$ of montelukast as monotherapy or as additional therapy to another antiasthmatic therapy (judged inadequate) for approximately four to six weeks between February and the end of July 2004. The results indicated that treatment with montelukast $(10 \mathrm{mg})$ provided an overall improvement in asthma symptoms for the majority of patients. For daytime asthma symptoms, $86.5 \%$ reported a strong or marked improvement, and $88.5 \%$ reported improvements in nighttime asthma symptoms. This improvement was associated with a reduction in the requirements for other asthma medications (eg, beta agonists and inhaled corticosteroids). For AR, overall improvement was reported with montelukast for the majority of patients. In fact, most patients reported improvements in all the symptoms of AR: $77.7 \%$ had red or burning eyes, $78.4 \%$ had watery eyes, $79.3 \%$ had nasal congestion, $81.7 \%$ had rhinorrhea, and $84 \%$ had sneezing or itching at the start of the study. Patients also reported a reduced use of AR medications 
(eg, nasal steroids, antihistamines). The majority of patients $(85.2 \%)$ also reported a QoL that was very good or good, and the therapy was well tolerated, with only 14 patients reporting 21 adverse events; none of these events were serious. This reallife setting confirmed the results from trials mentioned above, demonstrating that montelukast is a safe and effective treatment of both upper and lower airways in patients with asthma and AR.

\section{CONCLUSIONS}

AR and asthma are categorically similar disorders; they have an epidemiological connection of increasing prevalence, shared QoL issues and significant comorbidity - often with AR as a precursor to asthma. Pathophysiologically, these two disorders have similar cellular responses, with different symptoms based on the differences in the physical structures involved. Both disorders exhibit the inflammatory cascade and eosinophil infiltration of the nasal and bronchial epithelium. Finally, both disorders cause significant costs to the individual and to society.

AR and asthma often respond to the same treatments, which suggests that there is an intimate connection between the two. As a result, treatment guidelines have recognized the link between AR and asthma, and recommended that each condition be evaluated when a patient presents with either of the disorders. The guidelines further support a combined approach to treating both conditions for maximum therapy and a decreased medication load (35). Future guidelines may even consider recommending that treatment be aimed for total or overall respiratory symptom control. This approach would address both upper and lower airway symptoms in a more comprehensive manner.

In summary, the search for treatments to improve the symptoms of patients afflicted with AR and asthma has targeted the CysLTs, one group of the many inflammatory substances in the allergic response. Research has revealed that when the CysLTs are blocked, symptoms and function improve. Steroids and antihistamines do not block the action of leukotrienes, but the LTRA montelukast is an effective blocking agent. The evidence suggests that montelukast reduces the symptoms of AR, and is comparable with antihistamines and oral decongestants; it is also effective in both SAR and PAR, and improves lung functioning in asthma. In fact, results suggest that the effectiveness increases with greater levels of allergen exposure, and efficacy is also increased when asthma symptoms are more severe. As a result, montelukast is a suggested treatment for both conditions.

FUNDING: This study was supported by an unrestricted grant from Merck Frosst Canada.

\section{REFERENCES}

1. Skoner DP. Allergic rhinitis: Definition, epidemiology, pathophysiology, detection, and diagnosis. J Allergy Clin Immunol 2001;108(1 Suppl):S2-8.

2. Meltzer EO. Role for cysteinyl leukotriene receptor antagonist therapy in asthma and their potential role in allergic rhinitis based on the concept of "one linked airway disease". Ann Allergy Asthma Immunol 2000;84:176-85.

3. Wenzel S. Severe asthma in adults. Am J Respir Crit Care Med 2005;172:149-60.

4. Philip G, Nayak AS, Berger WE, et al. The effect of montelukast on rhinitis symptoms in patients with asthma and seasonal allergic rhinitis. Curr Med Res Opin 2004;20:1549-58.

5. Chapman KR, Ernst P, Grenville A, Dewland P, Zimmerman S. Control of asthma in Canada: Failure to achieve guideline targets Can Respir J 2001;8(Suppl A):35A-40A.

6. FitzGerald JM, Boulet LP, McIvor RA, Zimmerman S, Chapman KR. Asthma control in Canada remains suboptimal: The Reality of Asthma Control (TRAC) study. Can Respir J 2006;13:253-9

7. Simons FE. Allergic rhinobronchitis: The asthma-allergic rhinitis link. J Allergy Clin Immunol 1999;104:534-40.

8. Leynaert B, Neukirch F, Demoly P, Bousquet J. Epidemiologic evidence for asthma and rhinitis comorbidity. J Allergy Clin Immunol 2000;106(5 Suppl):S201-5.

9. Chapman KR, Cartier A, Hébert J, McIvor RA, Schellenberg RR. The role of omalizumab in the treatment of severe allergic asthma. Can Respir J 2006;13(Suppl B):1B-9B.

10. Kaiko GE, Horvat JC, Beagley KW, Hansbro PM. Immunological decision-making: How does the immune system decide to mount a helper T-cell response? Immunology 2008;123:326-38.

11. Reed SD, Lee TA, McCrory DC. The economic burdan of allergic rhinitis: A critical evaluation of the literature. Pharmacoeconomics 2004;22:345-61.

12. Weiss KB, Gergen PJ, Hodgson TA. An economic evaluation of asthma in the United States. N Engl J Med 1992;326:862-6.

13. Weiss KB, Sullivan SD. The health economics of asthma and rhinitis. I. Assessing the economic impact. J Allergy Clin Immunol 2001;107:3-8

14. Malone DC, Lawson KA, Smith DH, Arrighi HM, Battista C A cost of illness study of allergic rhinitis in the United States. J Allergy Clin Immunol 1997;99:22-7.

15. Price D, Zhang Q, Kocevar VS, Yin DD, Thomas M. Effect of a concomitant diagnosis of allergic rhinitis on asthma-related health care use by adults. Clin Exp Allergy 2005;35:282-7.

16. Thomas M, Kocevar VS, Zhang Q, Yin DD, Price D. Asthma-related health care resource use among asthmatic children with and without concomitant allergic rhinitis. Pediatrics 2005;115:129-34.

17. Leynaert B, Neukirch C, Liard R, Bousquet J, Neukirch F. Quality of life in allergic rhinitis and asthma. A population-based study of young adults. Am J Respir Crit Care Med 2000;162:1391-6.

18. Kay AB. Allergy and allergic diseases. First of two parts. N Engl J Med 2001;344:30-7.

19. Laitinen LA, Laitinen A, Haahtela T. Airway mucosal inflammation even in patients with newly diagnosed asthma. Am Rev Respir Dis 1993; 147:697-704

20. Inman MD, Ellis R, Wattie J, Denburg JA, O’Byrne PM. Allergen-induced increase in airway responsiveness, airway eosinophilia, and bone-marrow eosinophil progenitors in mice. Am J Respir Cell Mol Biol 1999;21:473-9.

21. Togias A. Unique mechanistic features of allergic rhinitis. J Allergy Clin Immunol 2000;105:S599-604.

22. Palframan RT, Collins PD, Williams TJ, Rankin SM. Eotaxin induces a rapid release of eosinophils and their progenitors from the bone marrow. Blood 1998;91:2240-8.

23. Statistics Canada. Persons with asthma, by age and sex (number of persons). <http://www40.statcan.ca/101/cst01/health49a.htm?sdi= asthma> (Version current at November 30, 2007).

24. van Cauwenberge P, Bachert C, Passalacqua G, et al. Consensus statement on the treatment of allergic rhinitis. European Academy of Allergology and Clinical Immunology. Allergy 2000;55:116-34.

25. Eder W, Ege MJ, von Mutius E. The asthma epidemic. N Engl J Med 2006;355:2226-35.

26. Von Ehrenstein OS, Von Mutius E, Illi S, Baumann L, Böhm O, von Kries R. Reduced risk of hay fever and asthma among children of farmers. Clin Exp Allergy 2000;30:187-93.

27. Stern DA, Riedler J, Nowak D, et al. Exposure to a farming environment has allergen-specific protective effects on TH2-dependent isotype switching in response to common inhalants. J Allergy Clin Immunol 2007;119:351-8.

28. Wahn U, von Mutius E, Lau A, Nickel R. The development of atopic phenotypes: Genetic and environmental determinants. Nestle Nutr Workshop Ser Pediatr Program 2007;59:1-11. 
29. Kohlhammer Y, Zutavern A, Rzehak P, Woelke G, Heinrich J. Influence of physical inactivity on the prevalence of hay fever. Allergy 2006;61:1310-5.

30. Kohlhammer Y, Döring A, Schäfer T, Wichmann HE, Heinrich J; KORA Study Group. Swimming pool attendance and hay fever rates in later life. Allergy 2006;61:1305-9.

31. Radon K, Schulze A. Adult obesity, farm childhood, and their effect on allergic sensitization. J Allergy Clin Immunol 2006;118:1279-83.

32. Braunstahl GJ, Kleinjan A, Overbeek SE, Prins JB, Hoogsteden HC, Fokkens WJ. Segmental bronchial provocation induces nasal inflammation in allergic rhinitis patients. Am J Respir Crit Care Med 2000;161:2051-7.

33. Braunstahl GJ, Overbeek SE, Kleinjan A, Prins JB, Hoogsteden HC, Fokkens WJ. Nasal allergen provocation induces adhesion molecule expression and tissue eosinophilia in upper and lower airways. J Allergy Clin Immunol 2001;107:469-76.

34. Bousquet J, Van Cauwenberge P, Khaltaev N; Aria Workshop Group; World Health Organization. Allergic rhinitis and its impact on asthma. J Allergy Clin Immunol 2001;108(5 Suppl):S147-334.

35. Platts-Mills TA. Allergen avoidance in the treatment of asthma and rhinitis. N Engl J Med 2003;349:207-8.

36. Minshall E, Ghaffar O, Cameron L, et al. Assessment by nasal biopsy of long-term use of mometasone furoate aqueous nasal spray (Nasonex) in the treatment of perennial rhinitis. Otolaryngol Head Neck Surg 1998;118:648-54.

37. Mucha SM, deTineo M, Naclerio RM, Baroody FM. Comparison of montelukast and pseudoephedrine in the treatment of allergic rhinitis. Arch Otolaryngol Head Neck Surg 2006;132:164-72.

38. Lima JJ, Zhang S, Grant A, et al. Influence of leukotriene pathway polymorphisms on response to montelukast in asthma. Am J Respir Crit Care Med 2006;173:379-85.

39. Chervinsky P, Philip G, Malice MP, et al. Montelukast for treating fall allergic rhinitis: Effect of pollen exposure in 3 studies. Ann Allergy Asthma Immunol 2004;92:367-73.

40. Philip G, Malmstrom K, Hampel FC, et al. Montelukast for treating seasonal allergic rhinitis: A randomized, double-blind, placebo-controlled trial performed in the spring. Clin Exp Allergy 2002;32:1020-8.

41. Patel R, Philip G, Yang W, et al. Randomized, double-blind, placebo-controlled study of montelukast for treating perennial allergic rhinitis. Ann Allergy Asthma Immunol 2005;95:551-7.

42. Chen ST, Lu KH, Sun HL, Chang WT, Lue KH, Chou MC. Randomized placebo-controlled trial comparing montelukast and cetirizine for treating perennial allergic rhinitis in children aged 2-6 yr. Pediatr Allergy Immunol 2006;17:49-54

43. Grainger J, Drake-Lee A. Montelukast in allergic rhinitis: A systematic review and meta-analysis. Clin Otolaryngol 2006;31:360-7.

44. Barnes N, Wei LX, Reiss TF, et al. Analysis of montelukast in mild persistent asthmatic patients with near-normal lung function. Respir Med 2001;95:379-86.

45. Biernacki WA, Kharitonov SA, Biernacka HM, Barnes PJ. Effect of montelukast on exhaled leukotrienes and quality of life in asthmatic patients. Chest 2005;128:1958-63.

46. Barnes N, Thomas M, Price D, Tate H. The national montelukast survey. J Allergy Clin Immunol 2005;115:47-54.

47. Piatti G, Ceriotti L, Cavallaro G, et al. Effects of zafirlukast on bronchial asthma and allergic rhinitis. Pharmacol Res 2003;47:541-7.

48. Price DB, Swern A, Tozzi CA, Philip G, Polos P. Effect of montelukast on lung function in asthma patients with allergic rhinitis: Analysis from the COMPACT trial. Allergy 2006;61:737-42. (Erratum in 2006;61:1153).

49. Busse WW, Casale TB, Dykewicz MS, et al. Efficacy of montelukast during the allergy season in patients with chronic asthma and seasonal aeroallergen sensitivity. Ann Allergy Asthma Immunol 2006;96:60-8.

50. Barnes ML, Menzies D, Fardon TC, Burns P, Wilson AM, Lipworth BJ. Combined mediator blockade or topical steroid for treating the unified allergic airway. Allergy 2007;62:73-80.

51. Virchow JC, Bachert C. Efficacy and safety of montelukast in adults with asthma and allergic rhinitis. Respir Med 2006;100:1952-9. 


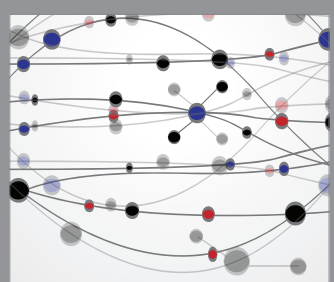

The Scientific World Journal
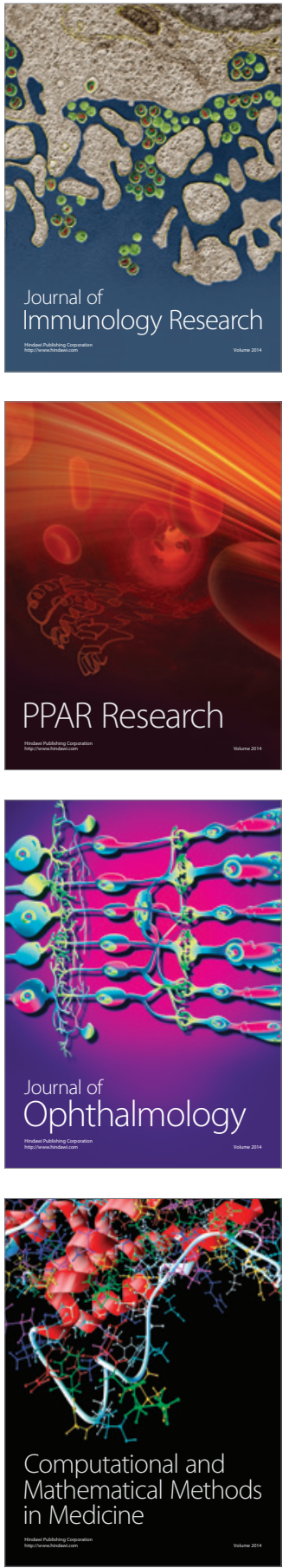

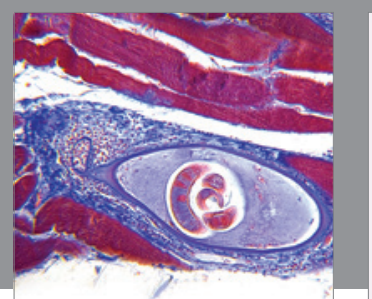

Gastroenterology Research and Practice

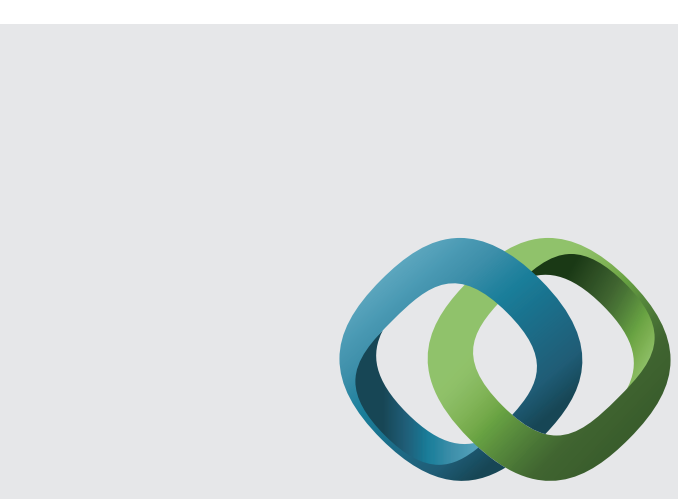

\section{Hindawi}

Submit your manuscripts at

http://www.hindawi.com
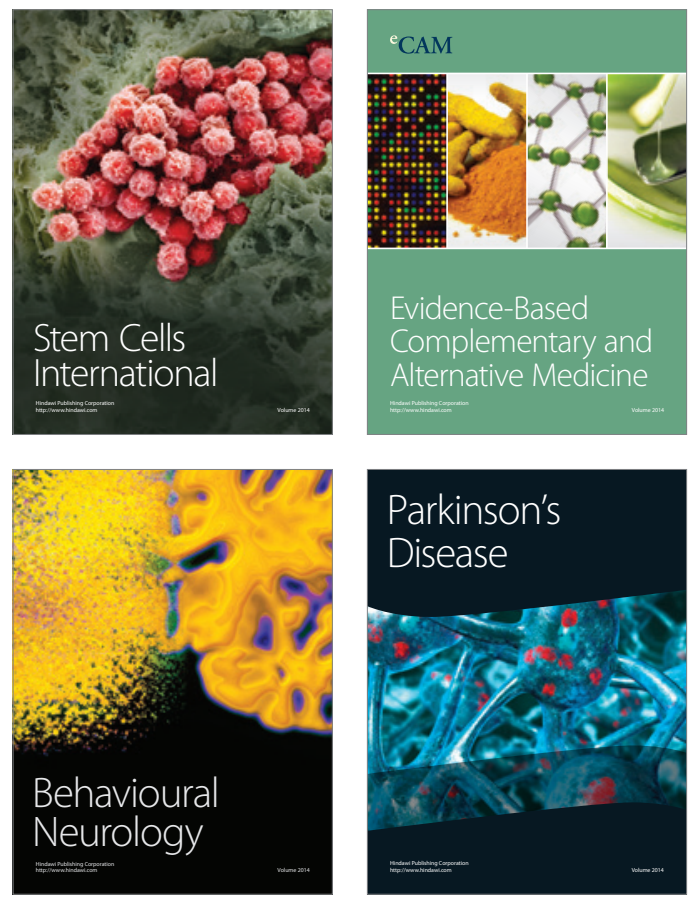
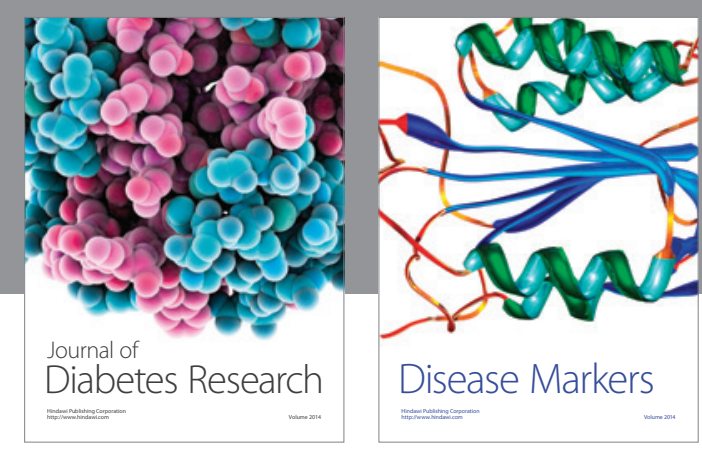

Disease Markers
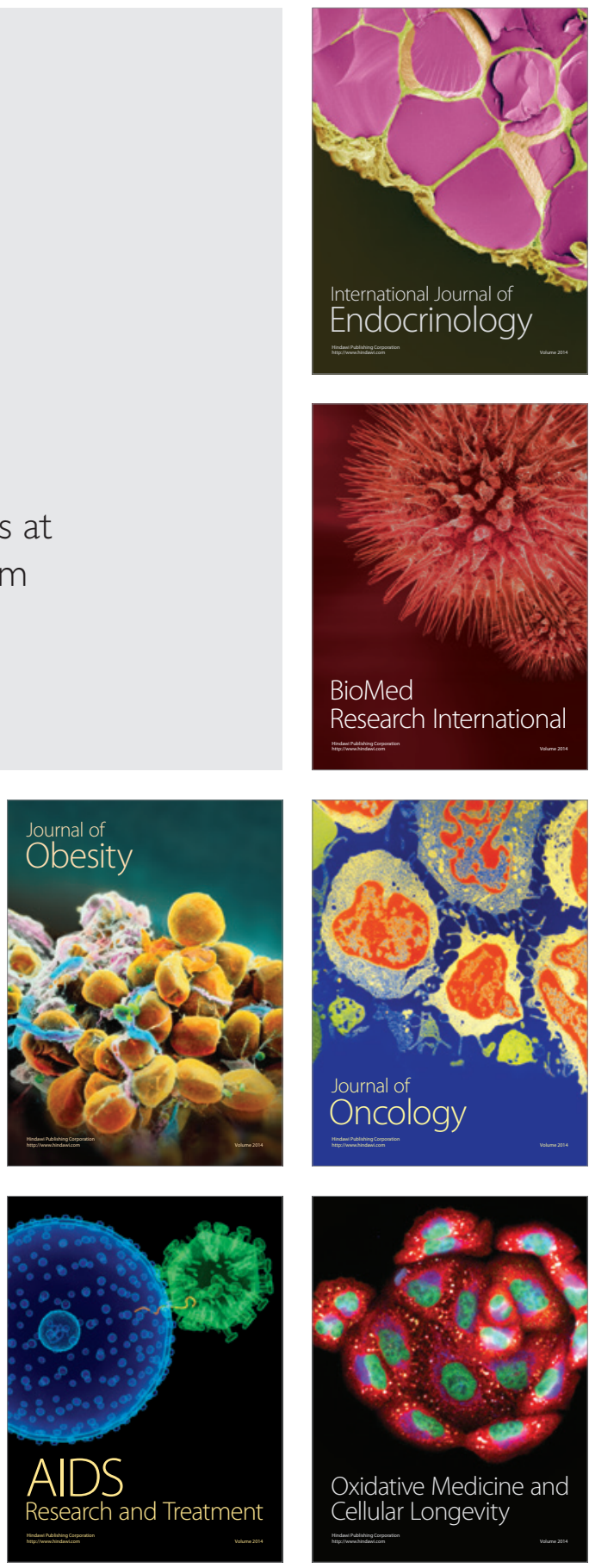